\title{
Mental stress post-COVID-19
}

\author{
Zafir Khan Mohamed Makhbul ${ }^{1}$, Zainab Ali Rawshdeh ${ }^{2}$ \\ ${ }^{1}$ Faculty of Economics and Management, University Kebangsaan Malaysia, Malaysia \\ ${ }^{2}$ College of Business Administration, Prince Sultan University, Saudi Arabia
}

\begin{tabular}{l}
\hline \hline Article Info \\
\hline Article history: \\
Received Jun 6, 2020 \\
Revised Dec 2, 2020 \\
Accepted Jan 4, 2021 \\
\hline
\end{tabular}

Keywords:

COVID-19

Mental

Pandemic

Stress

\begin{abstract}
Coronavirus disease (COVID-19) that is plaguing the world today surely carves a dark, unforgettable history. It has been declared a global pandemic by the World Health Organization (WHO). This shows that it has spread worldwide, transcending every border, and then finally penetrating every corner of the world. Despite its small size (measured in nanometer), its influence is great enough in triggering stress. As various countries declare a state of Emergency, restricted movement order and lockdown, varying reactions like sorrow, anxiety, misperception and fear have been ignited in the society. All of these have cumulatively caused stress among them. This current review paper summarizes and discusses the published literature addressing mental health concerns linked to the COVID-19 pandemic. Studies show that excessive stress causes the failure in the individual's mental and physical systems. The issue here is how the situation at the workplace, post-COVID-19 is different from the previous situation. Thus, the psychological preparation of every member in the organization is crucial to face the challenges coming their way. The available literature showed consensus that the COVID-19 pandemic not only affects physical health, but also stress and well-being. In conclusion, emotional well-being must be emphasized through training and human resource development strategy to prepare and empower the mentality of the organizational members to address this stress.
\end{abstract}

This is an open access article under the CC BY-SA license.

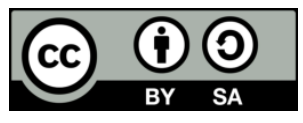

\section{Corresponding Author:}

Zafir Khan Mohamed Makhbul

Faculty of Economics and Management

University Kebangsaan Malaysia

Malaysia

Email: zafir@ukm.edu.my

\section{INTRODUCTION}

COVID-19 that has been hitting the world hard today is surely going to be very memorable. It has been declared as a global pandemic by the World Health Organisation (WHO). To date, COVID-19 has infected almost four Million people in 182 countries and has taken the lives of 270,000 people [1], making every individual panic and it is difficult to imagine what will happen after this.The impact is different to everyone as it can lead to ongoing fear. The impact of COVID-19 creates worry and restlessness among individuals all over the world [2]. COVID-19 pandemic gives a serious health crisis to the countries all over the world [3,4].

Although the size is very small, measuring in nanometer, it has a great influence as a trigger of stress. Psychological reaction due to the spread of the virus can trigger stress and affect mental health $[4,5]$. They also maintain that this feeling will be more obvious for individuals who are psychologically disturbed. When a lot of countries have declared emergency, movement control order and lockdown following COVID- 
19, various reactions like sorrow, anxiety, misperception, fear and anger have emerged in the society. All these have cumulatively triggered stress to them [6]. The assumption of food and necessity shortage, restricted movement and social activity, being separated from family and friends, losing jobs and the closing of businesses and the failure in accommodating for the cost of living for those receiving daily wages are among the examples of the worry that causes stress due to the spread of this virus. For the frontliners who manage and treat patients due to COVID-19 surely the level of stress that they feel intensifies. Other than facing the problems faced by the public, they are also directly involved to the risk of the virus itself. Every day that they go through is full of fear and worry. The frontliners have a great potential in experiencing a remarkable level of stress [7-9]. They state that the frontliners need to raise the awareness about COVID-19 symptoms, take enough rest, fulfill one's own needs and steer clear from the media coverage.

The limitless amount of information of COVID-19 from the social media whether it is truthful or bogus, can worsen the condition and contribute to anxiety in the society [8]. The reality shows that this pandemic gets stronge coverage from the social media which automatically adds to the worry and restlessness and further provoking extreme stress within individuals. COVID-19 triggers the impact of stress and mental health to those indirectly and directly having contact with the virus, those who have experienced mental health issues, high-risk frontliners and those who closely follow news updates about the virus in various sources of the social media [10].

However, many papers focused on the general effects of the COVID-19 pandemic on business and changes in workplace [11-16]. This current review paper summarizes and discusses the published literature addressing mental health distresses linked to the COVID-19 pandemic. Noticed that most literature target the workers in health sector to mention some [17-27]. Their outcomes are abridged in the Table 1.

Table 1. Studies linked mental health distresses to the COVID-19 pandemic

\begin{tabular}{l} 
Title \\
\hline The Effect of COVID-19 on Youth Mental Health \\
Mental health survey of 230 medical staff in a tertiary \\
infectious disease hospital for COVID-19 \\
Why all COVID-19 hospitals should have mental health \\
professionals: The importance of mental health in a \\
worldwide crisis!
\end{tabular}

COVID-19 and employees' mental health: stressors, moderators and agenda for organizational actions

COVID-19 and mental health: A review of the existing literature

The mental health of doctors during the COVID-19 pandemic

Affective temperament, attachment style, and the psychological impact of the COVID-19 outbreak: an early report on the Italian general population

Depression, anxiety, and stress and sociodemographic correlates among general Indian public during COVID-19

Immediate Psychological Responses and Associated Factors during the Initial Stage of the 2019 Coronavirus Disease (COVID-19) Epidemic among the General Population in China

Mental health problems and social media exposure during COVID-19 outbreak

The effectiveness of supervisor support in lessening perceived uncertainties and emotional xhaustion of university employees during the COVID-19 crisis: the constraining role of organizational intransigence Is returning to work during the COVID-19 pandemic stressful? A study on immediate mental health status and psychoneuroimmunity prevention measures of Chinese workforce

COVID 19 pandemic: Mental health challenges of internal migrant workers of India

Author Objective/Results

[28] Nearly $40.4 \%$ of the youth group had a tendency to have psychological problems.

[29] In COVID-19 epidemic, the incidence of anxiety and stress disorder is high among medical staff.

[30] Discusses the mental health consequences of the pandemic for the health care workers, people who are undergoing quarantine, people who are admitted to the COVID-19 hospitals, and those who have recovered from the infection.

[31] A negative impact of COVID-19 on individual's mental health. Stressors include perception of safety, threat and risk of contagion, in obesity versus the unknown, quarantine and confinement, stigma and social exclusion as well as financial loss and job insecurity

[32] Symptoms of anxiety and depression (16-28\%) and selfreported stress $(8 \%)$ are common psychological reactions to the COVID-19 pandemic and may be associated with disturbed sleep.

[33] The coronavirus disease 2019 crisis places additional pressure on doctors and on the healthcare system in general

[34] A relevant rate of individuals may have experienced psychological distress following the COVID-19 outbreak. Specific affective temperament and attachment features predict the extent of mental health burden.

[35] The prevalence rates of depression, anxiety and stress and their sociodemographic correlates among Indian population during the lockdown to contain the spread of COVID-19.

[36] The psychological impact, depressive symptoms, anxiety symptoms and stress levels of the outbreak.

[37] High prevalence of mental health problems, which positively associated with frequently social media exposure (SME) during the COVID-19 outbreak.

[38] Supervisor support has a negative effect on the perceived uncertainties of employees. Perceived uncertainties also significantly mediate the negative effect of supervisor support on the employees' emotional exhaustion.

[39] $10.8 \%$ of respondents met the diagnosis of post-traumatic stress disorder (PTSD) after returning to work. The respondents reported a low prevalence of anxiety (3.8\%), depression (3.7\%), stress (1.5\%) and insomnia (2.3\%).

[40] The interrelated and interdependent predisposing and causative factors for the development of psychological ill- 
Workplace responses to COVID-19 associated with mental health and work performance of employees in Japan

Can Psychological Resilience Protect the Mental Health of Healthcare Professionals during the COVID-19 Pandemic Period?

COVID-19 and Music Therapists' Employment, Service Delivery, Perceived Stress, and Hope: A Descriptive Study

Anxiety and depression symptoms of medical staff under COVID-19 epidemic in China

A New Rating Scale (SAVE-9) to Demonstrate the Stress and Anxiety in the Healthcare Workers During the COVID-19 Viral Epidemic

Mental Health Outcomes Among Frontline and SecondLine Health Care Workers During the Coronavirus Disease 2019 (COVID-19) Pandemic in Italy

Predicting Depression Among IT Sector Employees in India during COVID-19 Pandemic using Deep Neural Network and Supervised Machine Learning Classifiers: A Survey Approach

A rapid review investigating the potential impact of a pandemic on the mental health of young people aged 1225 years

Relationship quality and mental health during COVID-19 lockdown

Coronavirus Disease (COVID-19) and the risk of PostTraumatic Stress Disorder: A mental health concern in Nepal effects amongst internal migrant workers.

[41] Workplace measures may promote and maintain the mental health and work performance of employees during the COVID-19 epidemic.

[42] Attract attention to the mental issues and psychologica resilience of healthcare professionals who have the closest contact with the patients

[43] Determine the impact of the pandemic on the employment, service delivery, stress, and hope of music therapy professionals in the United States.

[44] Under outbreak of COVID-19, self-reported rates of anxiety symptoms and depression symptoms were high in investigated medical staff

[45] Scale has been developed as a tool for assessing work anxiety and stress in response to the viral epidemic of health professionals working to prevent the spread of the virus and to treat infected people.

[46] Reports on symptoms of posttraumatic stress disorder, depression, anxiety, and insomnia among health care workers in Italy during the coronavirus disease 2019 (COVID-19) pandemic.

[47] Predicting Depression Among IT Sector Employees in India during COVID-19 Pandemic using Deep Neural Network and Supervised Machine Learning Classifiers: A Survey Approach

[48] Brief the effect of a pandemic on the mental health of 12-25year-olds.

[49] Assess differences in several mental health and well-being measures according to relationship quality during the coronavirus disease (COVID-19) pandemic

[50] Determine mental health effect in Nepal.

\section{Stress issue post COVID-19}

Studies show that extreme stress can lead to the failure in the mental and physical systems of individuals to function, further creating an effect to the physiology, psychology and behavior [6, 4]. Briefly, stress is not the reason for a disease, but it weakens the immunization system and disturbs the capability of the body to overcome infection and disease. Thus, the stress that happens will fail the effort to control the growth of this virus. COVID-19 at the size of a nanometer gets its strength and energy from the human body for its own survival. The virus becomes more violent when an infected individual has a very weak immunity system [30]. This is very much linked with the fatality cases due to COVID-19 virus, most of which involve the aging population. This virus will somehow become weaker if the host (individual's body) has a strong immunity system if it is infected.

There is a group of individuals who ignores the danger of this virus. They live through their lives, even sometimes outside the norm that without them realizing, will exacerbate the situation. They will also create the stress to other people due to their violation of the movement control order (MCO). An individual will surely be stressed out because as he or she is really closely observing and curbing the spread of this dangerous virus, there are other individuals who turn a blind eye on this. This cannot be avoided because humans have various personalities. Behavioural science studies show that personality is a psychological component that describes one's personality, emotions, thoughts and behavior that are inherent in an individual and which make an individual different from one another [8]. It leads one's perception to be different from another person's perception with regard to his surroundings. To deal with people like this, a hasher method needs to be adopted because their action can only be changed by punishment or fines. When harsher punishments are imposed by the authority, it is able to create individual worry and they will realize the importance of obeying the order that has been issued.

\section{Too much dependency on technological gadgets}

Organisational productivity is expected to increase when group activities are minimized and social distancing is implemented. As it is, post COVID-19 witnesses all layers of the society to minimize face-toface communication, be it in groups or between one another. This is the reality that has to be accepted by all and it has become a new normal post COVID-19 where it will empower the close attachment between humans and the technology. Nonetheless, this high dependency on gadgets can lead to eye problems, like red 
eyes, watery eyes and deteriorating eyesight other than other impacts that are even more alarming, such as depression, fatigue, speech difficulty and psychological issues.

Other than that, the impact of COVID-19 will lead to the overuse of gadgets and the Internet among children and teenagers. If this is not properly monitored by family members, it will invite cyber crime and collapse the family institution. Surely, the concentration on various forms of applications through various gadgets also gives an impact towards the productivity. However, running away from gadgets and technology will not impede the spread of this pandemic. This is because almost all teaching and learning activities also aspects of life depend on gadgets. In fact, the use and dependency on the technology must be consistent with one's strength and weakness. The use of the technology requires wisdom and knowledge. It can be successful through ongoing education about the impact of continuous and uncontrollable use. Mental preparation and awareness must be present in every individual in facing the computerization technology, the automation and their challenges post COVID-19 in line with the development of Industry 4.0. Mental strength is crucial to produce emotional well-being and further achieve the life quality desired.

\section{Issues of xenophobia}

The impact of COVID-19 also influences the situations in our daily life including in the organization that will surely differ from the previous ones [34]. Social distancing is the immediate impact involving the separation of an individual from another individual or group from outside the organisation [10]. This limitation can influence one's perception towards another individual that will create xenophobia. With the global pandemic status, COVID-19 is expected to create a striking xenophobia.

Xenophobia is the fear and hatred towards something foreign related to a group, race or nation. This feeling is unavoidable because humans have their own perceptions and ways of thinking according to their own thinking framework, including their bad experiences related to COVID-19. The endless worry among the society due to xenophobia can trigger a very prominent stress. This needs to be addressed before the stress experienced due to xenophobia causes depression and leaves an impact on physiological health. Thus, at an early stage, organisations have to enhance the occupational safety and health procedure so that their citizens' confidence can be renewed to interact with foreigners and those outside their scopes. The function of occupational safety and health is seen as important in any institution when facing COVID-19 and postCOVID-19. A detailed occupational health practice procedure needs to be developed so that individuals feel comfortable in dealing with any individuals or groups that come from outside the organization, especially from abroad.

The action of the World Health Organisation (WHO) in not naming COVID-19 as Wuhan Virus is a very wise decision in curbing xenophobia. To the writer, WHO has learned from their past mistakes when they named the disease epidemic according to the name of the location like Ebola after the name of Ebola River, in Africa, MERS that started in the Middle East, or Spanish Flu that came from Spain. Naming the epidemic by location, where it all started can lead to remarkable xenophobia issues. Thus, everyone's awareness is anticipated so that the issue of xenophobia can be minimized.

Other than that, the authorities or the leadership of the organization must give an insight to the society that the virus knows no victim or locality, but it will spread wherever and to whoever it is. The feeling of xenophobia can also be minimized when an individual understands the cross-cultural aspect, and learns to accept the diversity of other people without prejudice to ensure self-development and organization.

Next, the authority or leaders of the organization together with the netizens must curb the spread of fake information about the disease especially news containing elements of hatred or racism. The abundant of unlimited information about COVID-19 from the social media be it honest or bogus, exacerbates the condition and contributes to xenophoba in the society. Viral information about a group or a country will make the issue of xenophobia even more serious and create extreme stress.

All stakeholders are obligated to promote their shared interests when the country is facing the pandemic, especially post COVID-19. Without accounting for skin colour, religious beliefs and politics, xenophobia can be minimised. Xenophobia, group discrimination, racism and boycotting a group in a society need to be stopped immediately as it is toxic to the country. If this is let on, it can create very prominent economic and humanity crises where finally it will leave a great impact in life.

\section{Managing change post COVID-19}

The change from the current normalcy to new normal must take place, although it is not easy for everyone to take it in. Researchers have found that individual mental block level influences the acceptance to change. Mental block would affect how a person thinks, perceives and acts. Actually, the main influence of mental block is confidence, feelings and other things that are already formed in the early phase of life. These are added by the influence of the surrounding and the normal occurrences that will make it more difficult for someone to accept change. 
We have to admit that every organisation would change or be changed due to COVID-19. The level of difficulty that one faces during the COVID-19 pandemic will determine their tendency to make the change. Studies show that the difficulty in accepting change can be due to employees' attitude that is comfortable with the structure and situations before COVID-19. If they have to change to New Normal, they need to go through new situations and environment that require some readjustment. Studies in change management show limited organization resources and the leadership style that obstruct the New Normal change that happens. Insufficient raw materials, too mechanistic and bureaucratic leadership style and low technology level are the factors that impede the application of New Normal to the organisation.

The change towards New Normal in the public health sector cannot be cast aside. If the people are asked to be more particular about self healthcare, the treatment and medical capacity by the authority must be improved. Besides that, organizations' occupational safety and health function must be empowered and improved. The occupational safety and health must be made more stringent to return the confidence of the human resource to improve their social relationships at the workplace.

Post COVID-19 also brings New Normal in the digitalization of businesses and services more extensively. The digital platform must be improved, advanced and ready earlier so that life affairs such as the process of teaching and learning in the educational institutions, work affairs in the organisations, sales of food and necessity are not interrupted.

The inclusive involvement of all stakeholders is in essential to make changes becoming New Normal and a way of life during and post-COVID-19. A more organic and open communication is needed to make everybody realizes of the need to change. Continuous communication and involvement will ignite honesty that can form trust and confidence. Through this commitment, trust and confidence towards New Normal will be formed and implemented successfully.

Other than that, the society has to have intellectuality and reasonable openness to help them accept this New Normal. This can be achieved through the process of human capital development in an ongoing manner, through training, education and individual development. Humanity aspects like skills, perception and hopes of individuals who have a continuity from the change formed must be emphasized so that every individual has a wide view about the need to change. Through the learning process in the human capital development, individuals will be more positive and ready to accept change.

\section{Psychological preparation post COVID-19}

The psychological impact is a very disconcerting aspect that will lead to stress in the society. In [5] expect that this COVID-19 pandemic will bring about a very obvious psychological impact especially to those who are, or who have experienced, having psychological disturbance. A few strategies that can be applied by every individual will be included in the following discussion.

\section{Self-acceptance}

Every individual must accept himself or herself the way they are, admit on their own strengths and weaknesses, and succumb to the fact that life does have its ups and downs. This conviction is able to form more confident individuals to facing future challenges.

\section{Personal growth and development}

Every individual must be prepared psychologically for change especially in terms of personal growth and development. The attribute and attitude of being open to knowledge and new experiences, easy to accept change and ready to change for the better will produce more confident citizens. Changes cannot be avoided during and post COVID-19. There could be individuals who need to change jobs and this requires them to have new knowledge and skills too. Thus, it is reasonable for every individual to try and improve their knowledge and skills so that they become more prepared in facing all possibilities.

\section{Purpose and meaning of life}

Every individual must realize the reality and the value of life. The paradigm shift and mind enhancement about the purpose of life in this world can bring about a very meaningful life, appreciating the blessings, determining life goals and striving towards achieving them, also learning to appreciate despite being tested, because in this way, every individual will be stronger and more persistent.

\section{Sensitive to the Surrounding}

Every individual must be sensitive psychologically towards the surroundings and the advantage in mastering it. Back then, the atmosphere is often said to influence human life, but the minds of individuals must be changed so that they believe that they are able to shape and influence their surroundings. All of these can be empowered through knowledge, skills and capability in controlling one's environment, solving problems and carrying out meaningful activities for own's and society's survivability. 


\section{Positive Relationships}

Every individual needs to realize about the significance of the social psychology aspect. To obtain strong social psychology, it has to begin with positive person-to-person relationships that will craft a more harmonious social situation. The ability to believe, love and support others (spouse, children, parents and colleagues) is an important input for the consolidation of the individual's social psychology that will minimize the stress faced during and post-COVID-19.

\section{CONCLUSION}

COVID-19 has created various forms of emotions among the organizational citizens surrounding aspects like their service requirements, future skills required and organizational environmental challenges. This causes worry and restlessness that lead to ongoing stress to just about anyone. The feelings of anxiety, fear and stress have to be curbed to assist individuals create their own coping strategies, protect themselves and improve their self-discipline. Thus, emotional well-being has to be emphasized through the training strategy and human resource development. This strategy is able to prepare and empower the mental health of the organizational citizens to face the stress during and post-COVID-19. Facing pandemics such as COVID19 requires all the parties to take the step of rehabilitation concretely and comprehensively in the many spectra of life. As an individual, we cannot put the burden on our superiors' shoulders. This is because no one is excused from this new normal, and every individual needs to increase their self-capability in facing the new more challenging reality. It may be seen as difficult now, but bear in mind that good practice makes perfect.

\section{ACKNOWLEDGEMENTS}

This research was funded by a research grant from Universiti Kebangsaan Malaysia (GUP-2020001).

\section{REFERENCES}

[1] Worldometer, COVID-19 Coronavirus Pandemic, 2020. [Online], Available: https://www.worldometers.info/

[2] Ahorsu, D.K., Lin, C-Y., Imani, V., et al., "The fear of COVID-19 scale: Development and initial validation," International Journal of Mental Health and Addiction, 2020.

[3] Anant Kumar., Rajasekharan Nayar, K., "COVID-19 and its mental health consequences," Journal of Mental Health, pp. 1-2, 2020.

[4] Sharma S., Bhatta J., "Public health challenges during the COVID-19 outbreak in Nepal: a commentary," Journal of Health Research, vol. 34, no. 4, pp. 373-376, 2020.

[5] Cullen W., Gulati G., Kelly B.D., "Mental health in the COVID-19 pandemic," QJM: An International Journal of Medicine, vol. 113, no. 5, pp. 311-312, 2020.

[6] Bao, Y., Sun, Y., Meng S., et al., "2019-nCoV epidemic address mental health care to empower society," Lancet, vol. 395, no. 10224, pp. e37-e38, 2020.

[7] Banerjee, D., "The COVID-19 outbreak: Crucial role the psychiatrists can play," Asian Journal Psychiatry, vol. 50, 2020.

[8] Gao, J., Zheng, P., Jia Y., et al., "Mental health problems and social media exposure during COVID-19 outbreak," PLoS ONE, vol. 15, no. 4, 2020.

[9] Cullen W., Gulati G., Kelly B.D., "Mental health in the COVID-19 pandemic," QJM: An International Journal of Medicine, vol. 113, no. 5, pp. 311-312, 2020

[10] Fiorillo, A., Gorwood, P., "The consequences of the COVID-19 pandemic on mental health and implications for clinical practice," European Psychiatry, vol. 63, no. 1, no. e32, 2020.

[11] Spurk, D., Straub, C., "Flexible employment relationships and careers in times of the COVID-19 pandemic," Journal of Vocational Behavior, vol. 119, 2020, doi: https://doi.org/10.1016/j.jvb.2020.103435

[12] Hite, L. M., McDonald, K. S., "Careers after COVID-19: challenges and changes," Human Resource Development International, vol. 23, no. 4, pp. 427-437, 2020.

[13] Kniffin, K. M., Narayanan, J., Anseel, F., et al., "COVID-19 and the workplace: Implications, issues, and insights for future research and action,” American Psychologist, pp. 1-15, 2020. doi: https://doi.org/10.31234/osf.io/gkwme, 2020.

[14] Bartik, A. W., Bertrand, M., Cullen, Z., et al., "The impact of COVID-19 on small business outcomes and expectations," Proceedings of the National Academy of Sciences, vol. 117, no. 30, pp. 17656-17666, 2020.

[15] Verma, S., Gustafsson, A., "Investigating the emerging COVID-19 research trends in the field of business and management: A bibliometric analysis approach," Journal of Business Research, vol. 118, pp. 253-261, 2020.

[16] McLean, G. N., Jiantreerangkoo, B., "The role of national HRD in an era of COVID-19," Human Resource Development International, vol. 23, no. 4, pp. 418-426, 2020.

[17] El-Hage, W., Hingray, C., Lemogne., et al., "Health professionals facing the coronavirus disease 2019 (COVID-19) pandemic: What are the mental health risks?," L'Encephale, vol. 46, no. 3S, pp. S73-S80, 2020. 
[18] Wang, Y., Jia, X., Song, J., et al., "Mental health status of medical staff during the outbreak of coronavirus disease 2019," Medical Journal of Wuhan University, vol. 41, no. 5, 2020.

[19] Ning X., Yu F., Huang, Q., et al., "The mental health of neurological doctors and nurses in Hunan Province, China during the initial stages of the COVID-19 outbreak," BMC Psychiatry, vol. 20, no. 436, 2020.

[20] Ani-Amponsah, M., Awuni, S.A., Empalba, et al., "Mental health stress and coping strategies among healthcare workers at the Bolgatanga Regional Hospital," Diverse Journal of Multidisciplinary Research, vol. 2, no. 6, pp. 4860,2020

[21] Azoulay E., Alain C., Fabrice B., et al., "Symptoms of anxiety, depression and peritraumatic dissociation in critical care clinicians managing COVID-19 patients: A cross-sectional study," American Journal of Respiratory and Critical Care Medicine, vol. 202, no. 10, pp. 1388-1398, 2020.

[22] Shrestha, R., Bijay, K., Suman, R., Santoshi, A., "Anxiety, depression and functional impairment during the COVID-19 pandemic among health care workers," Research Square, pp. 1-10, 2020, doi: https://doi.org/10.21203/rs.3.rs-66245/v2

[23] Cheng W., Zhang F., Liu Z., et al., "Psychological health support scheme for medical teams in COVID-19 outbreak and its effectiveness," General Psychiatry, vol. 33, no. 5, 2020.

[24] Lusher J., Murrell A., Mafuva C., Awire E., "COVID-19 pandemic and the surge of panic attacks among NHS nursing staff: An ethnographical perspective," J Adv Nurs, pp. 1-2, 2020, doi: 10.1111/jan.14508.

[25] Yang C., Zhou B., Wang J., Pan S. "The effect of a short-term Balint group on the communication ability and selfefficacy of pre-examination and triage nurses during COVID-19," Journal Clinical Nursing, pp. 1-18, 2020, doi: 10.1111/jocn.15489.

[26] Huffman E. M., Dimitrios I. A., Nicholas E. A., et al., "How resilient is your team? Exploring healthcare providers' well-being during the COVID-19 pandemic," The American Journal of Surgery, 2020.

[27] Sankar P., Waseem N. A., Vineetha M. K., et al., "Effects of COVID-19 lockdown on type 2 diabetes, lifestyle and psychosocial health: A hospital-based cross-sectional survey from South India," Diabetes \& Metabolic Syndrome: Clinical Research \& Reviews, vol. 14, no. 6, 1815-1819, 2020, https://doi.org/10.1016/j.dsx.2020.09.005.

[28] Liang L., Ren H., Cao R., et al., "The effect of COVID-19 on youth mental health," Psychiatric Quarterly, vol. 91, pp. 841-852, 2020.

[29] Huang J. Z., Han M. F., Luo T. D., et al., "Mental health survey of 230 medical staff in a tertiary infectious disease hospital for COVID-19," Chinese Journal of Industrial Hygiene and Occupational Diseases, vol. 38, no. 3, 2020, doi: 10.3760/cma.j.cn121094-20200219-00063.

[30] Grover S., Dua D., Sahoo S., et al., "Why all COVID-19 hospitals should have mental health professionals: The importance of mental health in a worldwide crisis!," Asian Journal of Psychiatry, vol. 51, 2020, doi: 10.1016/j.ajp.2020.102147.

[31] Hamouche S., "COVID-19 and employees' mental health: stressors, moderators and agenda for organizational actions," Emerald Open Research, vol. 2, no. 15, pp. 1-11, 2020.

[32] Rajkumar R.P., "COVID-19 and mental health: A review of the existing literature," Asian Journal Psychiatry, vol. 52, p. 102066, 2020.

[33] Galbraith N., Boyda D., McFeeters D., Hassan, T., "The mental health of doctors during the COVID-19 pandemic," BJPsych bulletin, 28: 1-4, 2020.

[34] Moccia L., Janiri D., Pepe M., Dattoli L., et al., "Affective temperament, attachment style, and the psychological impact of the COVID-19 outbreak: An early report on the Italian general population," Brain, Behavior and Immunity, vol. 87, pp. 75-79, 2020.

[35] Verma S., Mishra A., "Depression, anxiety, and stress and socio-demographic correlates among general Indian public during COVID-19," International Journal of Social Psychiatry, vol. 66, no. 8, pp. 756-762, 2020.

[36] Wang C., Pan R., Wan X., et al., "Immediate psychological responses and associated factors during the initial stage of the 2019 coronavirus disease (COVID-19) epidemic among the general population in China," International Journal of Environmental Research and Public Health, vol. 17, no. 5, pp. 1-25, 2020.

[37] Gao J., Zheng P., Jia Y., Chen H., et al., "Mental health problems and social media exposure during COVID-19 outbreak. PloS One, vol. 15, no. 4, p. 0231924, 2020.

[38] Charoensukmongkol P., Phungsoonthorn T., "The effectiveness of supervisor support in lessening perceived uncertainties and emotional exhaustion of university employees during the COVID-19 crisis: the constraining role of organizational intransigence," The Journal of General Psychology, pp. 1-20, 2020.

[39] Tan W., Hao F., McIntyre R. S., et al., "Is returning to work during the COVID-19 pandemic stressful? A study on immediate mental health status and psychoneuroimmunity prevention measures of Chinese workforce," Brain, Behavior, and Immunity, vol. 87, pp. 84-92, 2020.

[40] Choudhari R., "COVID-19 pandemic: Mental health challenges of internal migrant workers of India," Asian Journal of Psychiatry, vol. 54: 102254, 2020.

[41] Sasaki N., Kuroda R., Tsuno K., Kawakami, N., "Workplace responses to COVID-19 associated with mental health and work performance of employees in Japan," Journal of Occupational Health, vol. 62, no. e12134, pp. 1-6, 2020.

[42] Bahar A., Koçak H. S., Bağlama S. S., Çuhadar D., "Can psychological resilience protect the mental health of healthcare professionals during the COVID-19 pandemic period?," Dubai Medical Journal, pp. 1-7, 2020.

[43] Gaddy S., Gallardo R., McCluskey S., et al., "COVID-19 and music therapists' employment, service delivery, perceived stress, and hope: A descriptive study," Music Therapy Perspectives, 2020.

[44] Liu Y., Chen H., Zhang N., et al., "Anxiety and depression symptoms of medical staff under COVID-19 epidemic in China," Journal of Affective Disorders, vol. 278, pp. 144-148, 2020. 
[45] Tavormina G, Tavormina M.G.M., Franza F, et al., "A new rating scale (save-9) to demonstrate the stress and anxiety in the healthcare workers during the COVID-19 viral epidemic," Psychiatr Danub, vol. 32, no. 1, pp. 5-9, 2020.

[46] Rossi R, Socci V, Pacitti F, et al., "Mental health outcomes among frontline and second-line health care workers during the coronavirus disease 2019 (COVID-19) pandemic in Italy," JAMA Netw Open, vol. 3, no. 5, p. e2010185, 2020.

[47] Kaman S., Ishani V., "Predicting depression among it sector employees in India during COVID-19 pandemic using deep neural network and supervised machine learning classifiers: A survey approach," International Journal of Multidisplinary Educational Research, vol. 9, no. 8, pp. 2020.

[48] O'Reilly A., Tibbs M., Booth A., et al., "A rapid review investigating the potential impact of a pandemic on the mental health of young people aged 12-25 years," Irish Journal of Psychological Medicine, pp. 1-33, 2020, doi: doi:10.1017/ipm.2020.106.

[49] Pieh C, O'., Rourke T, Budimir S., Probst T., "Relationship quality and mental health during COVID-19 lockdown," PLOS ONE, vol. 15, no. 9, 2020.

[50] Asim M., van Teijlingen E., Sathian B., "Coronavirus disease (COVID-19) and the risk of post-traumatic stress disorder: A mental health concern in Nepal," Nepal Journal Epidemiology, vol. 10, no. 5, pp. 841-844, 2020. 